\title{
Xanthogranulomatous Oophritis Masquerading as Ovarian Neoplasm: A case report
}

\author{
Syed Besina, ${ }^{1}$ Bashir Naheena ${ }^{2}$ \\ Department of Pathology, Sher-e-Kashmir institute of medical Sciences, Soura
}

\section{A B S T RA C T}

\begin{abstract}
Xanthogranulomatous inflammation is a special form of chronic inflammation that destroys normal tissue of affected organs which get replaced by chronic inflammatory cell infiltrate admixed with foci or sheets of foam cells, fibroplasias and vascular proliferation. Only a few cases of xanthogranulomatousoophoritis have been reported.We report a case of 35 year old female who presented with lower abdominal pain and polymennorhea. A total hysterectomy with bilateral salpingoopherectomy was performed on the suspicion of an ovarian neoplasm.

Keywords: Ovary, neoplasm, xanthogranulomatous, oophritis

JMS: 2019;22(1):71-74 DOI: https://doi.org/10.33883/jms.v22i1.401
\end{abstract}

Xanthogranulomatous inflammation is a special form of chronic inflammation that is destructive to normal tissue of affected organs. ${ }^{1}$ It is characterized by the presence of a large number of lipid-containing macrophages with an admixture of lymphocytes, plasma cells and neutrophils ${ }^{2}$. Most commonly affected organ is kidney followed by gallbladder ${ }^{3}$.Female genital tract is an unusual location for xanthogranulomatous inflammation and if present usually involves the endometrium. Only a few cases of xanthogranulomatousoophoritis have been reported ${ }^{4,5}$

\section{CASE REPORT}

A 35-year-old woman originally presented with lower abdominal pain and polymennorhea along with intermittent fever since three months. She had no co existing medical or surgical co-morbidity. On examination, a large mass filling the right pelvic cavity was noted.CA-125 levels were elevated (171.4)in the patient.

She was evaluated for the pelvic mass and a CT scan performed revealed a large $5.8 \times 4.3 \mathrm{cmcomplex} \mathrm{solid} \mathrm{cystic}$ mass with multiple enhancingseptations in the right adnexa.No calcifications were seen.Left adnexa showed a $3 \times 2 \mathrm{~cm}$ follicular cyst.Few retroperitoneal nodes were also

\begin{tabular}{|l|l|}
$\mid$ & Website: \\
\hline Www.jmsskims.org
\end{tabular}

noted.

In view of the above findings an ovarian neoplasm was suspected and hysterectomy alongwith bilateral salpingoopherectomy was performed.Intraoperatively a right adnexal mass adherent to the uterus and adjacent peritoneum was found. Minimal peritoneal and pelvic nodes were seen.

We received a specimen of uterus along with right tuboovarian mass and left fallopian tube with ovaryalongwithomental fat and pelvic nodes. The mass measured 9x8x4 cm having an irregular external surface and was adherent to the uterus. Cut section wasgreyish white, firm along with focal cystic and necrotic areas. Left ovary was edematous measuring $5 \times 4 \times 3 \mathrm{~cm}$, Cut section showed a $2 \times 2 \mathrm{~cm}$ follicular cyst. Uterus measured $8.5 \times 4 \times 3 \mathrm{~cm}$ and cut section was unremarkable. (Fig 1)

Correspondence:

Dr. Naheena Bashir, M.D.

Senior Resident, Department of Pathology SKIMS

Email:naheena786@gmail.com

How to cite this article: Besina $S$, Naheena $B$. XanthogranulomatousOophritis masquerading as ovarian neoplasm: a case report. jms [Internet]. 2019Mar.29 [cited 2019Apr.13];22(1). Available from: http://www.jmsskims.org/ index.php/jms/article/view/401

Received: 15-02-2019 Accepted: 25-03-2019 
Besina S; et al; Xanthogranulomatous Oophritis Masquerading as Ovarian Neoplasm

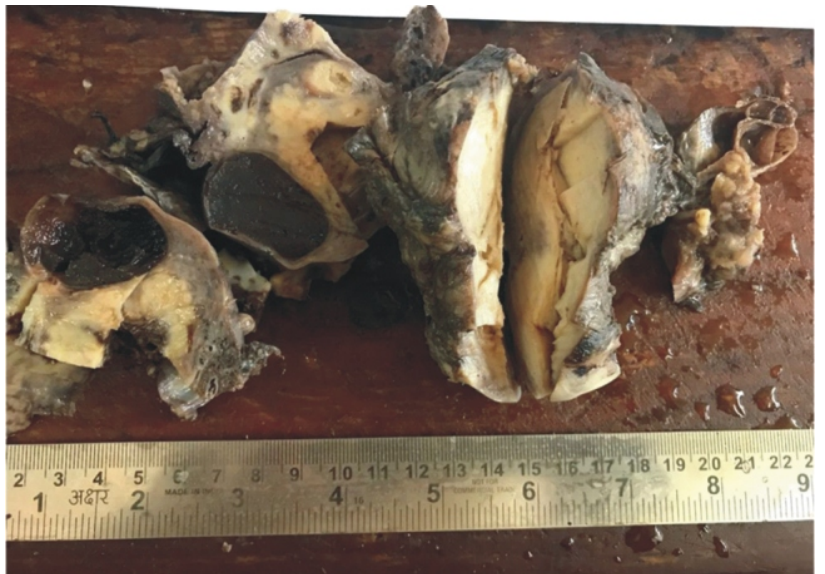

Fig 1: Right ovary shows the mass- grayish white, firm along with focal cystic and necrotic areas.Left ovary shows follicular cyst

Histologically, right ovarian stroma was almost completely replaced with dense inflammatory cell infiltrate consisting of large number of lipid laden macrophages, accompanied by lymphocytes and plasma cells alongwithareas of necrosis. Fibrosis along with vascular proliferation was also present.There was no evidence of malignancy in the sections studied from the tubo-ovarian mass. Sections from the left ovary,left fallopian tube and uterus were unremarkable.(Fig $2 \& 3$ )
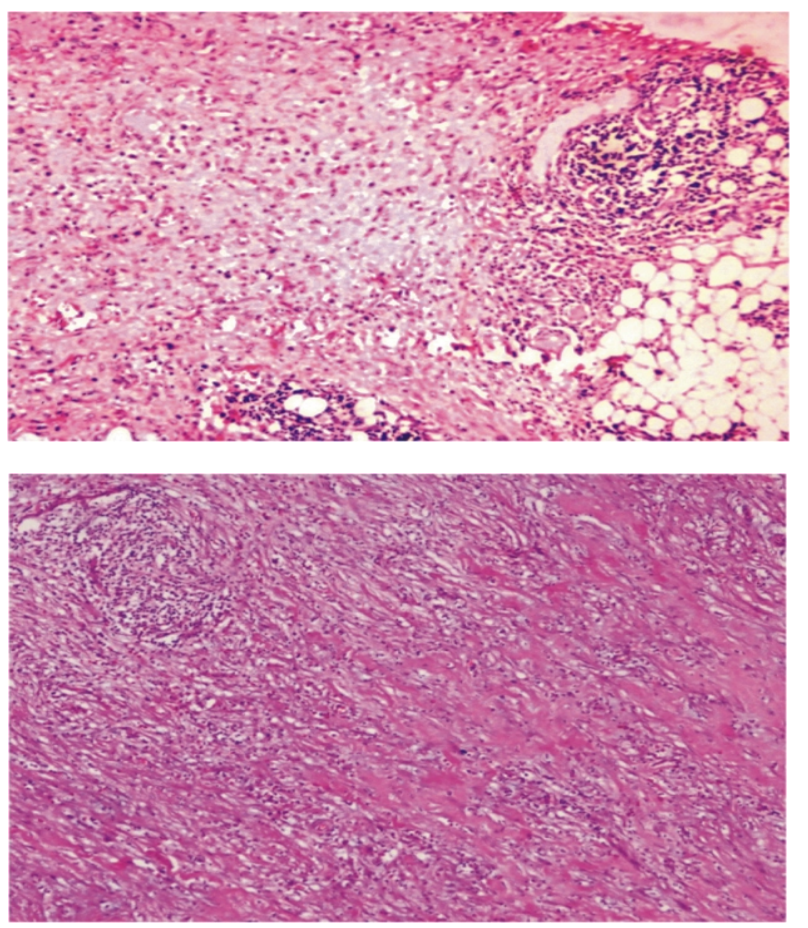

Fig 2 \& 3: Ovarian stroma almost completely replaced with lipid laden macrophages, accompanied by lymphocytes and plasma cellsalong with fibrosis and vascular proliferation. (H and E X 400)

\section{DISCUSSION}

Xanthogranulomatous inflammation is a rare clinical condition. However, when encountered it occurs commonly in the lung, orbit, renal and biliary system ${ }^{3}$. It is a special form of chronic inflammation that is destructive to normal tissue of affected organs ${ }^{1}$.Xanthogranulomatous inflammation occurring in female genital tract affects endometrium, fallopian tubes or ovaries focally or entirely, which clinically forms mass like lesion in the pelvic cavity and invades the surrounding tissues ${ }^{6 .}$ Kunakemakorn was the first to describe xanthogranulomatous inflammation of serosa ofuterus, left fallopian tube and ovary in his report of inflammatory pseudotumor in the pelvis in $1976^{7}$.Only 16 cases of xanthogranulomatous inflammation involving the ovary have been reported until datewith very few from Indian literature ${ }^{8}$.The clinical picture,radiological findings and the gross findinds in a xanthogranulomatous ovary are amenable to confusion with an ovarian malignancy.

The etiopathogenesis of this condition has been debated over years and is still unclear.Proposedrisk factors include chronic bacterial infections, ineffective antibiotic therapy, use of IUCD, abnormalities in lipidmetabolism, endometriosis, foreign material such as retained suture material ${ }^{9}$.Our patient had been on an antibiotic therapy for a while and was also using IUCD.Bacteria like Bacteroidesfragilis, Proteus, Escherichia coli, Staphylococcus aureus, Salmonella typhican be considered in the pathogenesis ofxanthogranulomatousoophoritis ${ }^{10}$ .Punia et al reported xanthogranulomatousoophritis as a late sequelae of inadequatelytreated pelvicinflamatory disease. ${ }^{11}$ Singh et al reported a case 3 yrs following uterine artery embolisation ${ }^{12} U$ R Singh et al reported xanthogranulomatousoophritisas acomplication of typhoid. ${ }^{13}$

The age group of patients in previously reported cases varied mostly from 17 to 73 years ${ }^{13,14,15}$ with the youngest case reported in a 2 yrs old female in $2015^{15}$. The clinical presentation include fever,abdominal pain ,menorrhagia,abdominal mass, anemia. The involved ovary in each of the previous reported cases was replaced by solid,yellow,lobulated masses that was well circumscribed and showed xanthogranulomatous inflammation on microscopy ${ }^{16,17}$

USG may reveal a solid-cystic mass with septations and 
Besina S; et al; Xanthogranulomatous Oophritis Masquerading as Ovarian Neoplasm

clear margins.A CT scan may reveal a well-defined solid mass with altered signal intensity ${ }^{4}$.Presence of nonenhancing intramural nodules in the thickened wall of an ovarian cystic mass with high signal intensity on T2weighted images and low signal intensity on T1-weighted images may be a unique MR indicator of xanthogranulomatous oophoritis ${ }^{18,19}$.CT and MR findings are however usually nonspecific for this condition as they are frequently misdiagnosed as malignant ovarian tumors due to appearances unusual for tuboovarian abscesses ${ }^{20}$

The condition needs to be differentiated from various neoplastic and non neoplasticconditions. The differential diagnosis includes non neoplastic conditions like tuberculosis, fungal infections, malakoplakia and neoplastic conditions like lymphoma, leukaemia, sclerosing stromal tumor and malignant small round cell tumor. Definitive diagnosis, however, can only be made on microscopy. Morphologically, the normal ovarian structure is destroyed and replaced by chronic inflammatory cell infiltrate admixed with foci or sheets of foam cells, fibroplasia, chronic inflammatory cell infiltrate and vascular proliferation similar to the picture seen in our case.The pathologist however has to be very cautious as a mild increase in any of these components can lead to misdiagnosis. Immunohistochemistry for CD68, Vimentin, $\mathrm{S} 100$ are helpful ${ }^{4,5}$ in confirming the diagnosis.

The treatment of choice for xanthogranulomatousoophritis isoopherectomy.Antibiotics have been attempted but they have been unsuccessful in reducing the size of the mass ${ }^{7}$.Since this is associated with many other conditions like pelvic inflamatory diseases, endometriosis and intrauterine death,the patient needs to be kept on a close follow up.

\section{CONCLUSION}

Xanthogranulomatousoophritis is a rare benign condition with very few cases reported in the literature. It can be easily misinterpreted as malignancy by the clinical picture and various imaging modalities making histopathology the most definitive method of diagnosing the condition. Also, patients on long term antibiotics, endometriosis and pelvic inflammatory diseases need to be kept on a close follow up as they are more prone to get xanthogranulomatous oophritis.

\section{Conflict of interest : Nil.}

Financial Source: Nil

\section{REFERENCES}

1. Franco V, Florena AM, Guarneri G, Gargano G. Xanthogranulomatous salpingitis: case report and review of the literature. Acta Eur Fertil.1990;21:197199

2. Mittal B V, Badhe B P. Xanthogranulomatous pyelonephritis (a clinicopathological study of 15 cases): Journal of Postgraduate Medicine. 1989; 35(4): 209214.

3. Guzmán G-Valdivia. Xanthogranulomatous cholecystitis: 15 years' experience. World Journal of Surgery. 2004; 28 (3): 254257.

4. Zhang XS, Dong HY, Zhang Ll, Desouki MM, Zhao C. Xanthogranulomatous inflammation of the female genital tract: report of three cases. J Cancer. 2012;3:100-6.

5. Kalloli M, Bafna UD, Mukherjee G, Devi UK, Gurubasavangouda, Rathod PS. A rare Xanthogranulomatous Oophoritis presenting as ovarian cancer. Online J Health Allied Scs. 2012;11(2):11

6. Shukla S, Pujani M, Singh SK, Pujani M. Xanthogranulomatous oophoritis associated with primary infertility and endometriosis. Indian J Pathol Microbiol 2010;53:197-198.

7. Kunakemakorn P, Ontai H. Pelvic inflammatory pseudotumor: A case report. Am J Obstet Gynecol. 1976; $26: 286-287$

8. Naik M, Madiwale C, Vaideeswar P. Xanthogranulomatous oophritis-a case report.Indian J Pathol Microbiol,1999;42:89-91

9. Tai S, Liang C. A case of genitourinary xanthogranulomatous inflammation.GynecolObstet 2013;160:1-3.

10. Gray Y, Libbey NP. Xanthogranulomatoussalpingitis and oophoritis: A case report and review of the literature. Arch Pathol Lab Med. 2001; 125: 260-263.

11. Punia RS, Aggarwal R, Amanjit, Mohan H. Xanthogranulomatous oophoritis and salpingitis:late sequelae of inadequately treated staphylococcal PID. 
Besina S; et al; Xanthogranulomatous Oophritis Masquerading as Ovarian Neoplasm

Indian J Pathol Microbiol. 2003 Jan; 46(1): 80-1.

12. Singh N, Tripathi R, Mala YM, Arora S. Xanthomatousoophoritis following uterine artery embolisation: Successful conservative surgical management with favourable outcome. BMJ Case Rep 2013;2013:pii: bcr2013010184.

13. Singh UR, Revathi G, Gita R. Xanthogranulomatous oophoritis: an unusual complication of typhoid. J Obstet Gynaecol (Tokyo 1995). 1995 Oct; 21(5): 4336

14. Hemalatha AL, Rao S, Deepak KB, Gayathri MN, Manjunath BS, Rathna S. Xanthogranulomatous salpingo-oophoritis: a rare entity at an exceptional site. Indian J Pathol Microbiol. 2007 Jul; 50(3): 607-9.

15. Tanwar H, Joshi A, Wagaskar V, Kini S. Xanthogarnulomatous oophritis:the youngest documented case report.Case report in obstetgynaecol 2015-237250
16. Ladefoged C, Lorentzen M. Xanthogranulomatous inflammation of the female genital tract. Histopathology 1988;13:541-51.

17. Pace EH, Voet RL, Melancon JT. Xanthogranulomatous oophoritis an inflammatory pseudotumor of the ovary. Int J Gynecol Pathol 1984;3:398-402.

18. Jung SE, Lee JM, Lee KY, Han KT, Hahn ST. Xanthogranulomatous oophoritis: MR imaging findings with pathologic correlation. AJR Am J Roentgenol. 2002; 178: 74951.

19. Kim SH, Yang DM, Kim KA. Unusual causes of tuboovarian abscess: CT and MR imaging findings. Radiographics .2004; 24: 157589.

20. SunHoKim, SeunghyuiKim,Dal Mo Yang, Kyeong A. Kim. Unusual Causes of tubo ovarian abscess: CT and MR Imaging findings: Radiographics 2004;24(6)1575-1589 